\title{
Expression of p53, bcl-2, bax and bcl-xl in ductal carcinoma in situ (DCIS) of the breast
}

\author{
Amal N Ahmad, ${ }^{a}$ MD; Eman MS Muhammad, $b$ MD, PhD; \\ Asem Elsani M Ali, ${ }^{c} M D$
}

a) Department of Pathology, Sohag Faculty of Medicine, Egypt.

b) Department of Pathology, Sohag Faculty of Medicine, Egypt.

c) Department of Surgery, Sohag Faculty of Medicine, Egypt.

Background: DCIS is a malignant proliferation of mammary ductal epithelial cells without invasion beyond the basement membrane. Bcl-2, bax, bcl-xl and $p 53$ are implicated in regulation of apoptosis. This study aimed to clarify the role of these gene products in DCIC.

Patients and methods: Immunohistochemical staining of 13 cases of DCIS with bcl-2, bax, bcl-xl and p53 was performed.

Results: DCIS was graded into; $42 \%$ of low, $16 \%$ of intermediate, and $42 \%$ of high grade cases. P53 was negative in all low grades, positive in $66.7 \%$ intermediate grade, and in all high grade DCIS. BCl-2 was positive in all DCIS with variable intensities. Bax was positive in $80 \%$ of low grade, $100 \%$ of intermediate grade, and in $100 \%$ of high grade DCIS. Bcl-xl was positive in $80 \%$ of low grade, and in all intermediate and high grade DCIS. P53 was inversely correlated with bcl-2 expression in DCIS $(p<0.02)$. Insignificant positive correlation was present between $p 53$ and bax expression and between 553 and bcl-xl expression in DCIS. An inverse correlation was present between bcl-2 and bcl-xl expression and between bcl-2 and bax expression in DCIS ( $p<0.01$ for each). Positive correlation was present between bax and $b c l-x l$ expression $(p<0.000)$ in DCIS.

Conclusions: p53 mutation is an early event in the evolution of breast cancer and its expression correlates with high grade lesions. Strong positive correlation between bax and bcl-xl, but the prognostic value of bcl-2 protein family in DCIC is still in need to more studies to be clarified.

Key words: Ductal carcinoma in situ, bcl-2 bax, bcl-xl and p53.

Abbreviations: Ductal carcinoma in situ (DCIS), carcinoma in situ (CIS), invasive carcinoma (IC), inhibitor of apoptosis proteins (IAP), Hematoxylin and Eosin (H\&E), catalogue number (Cat \#), phosphate buffered solution (PBS), staining intensity (SI), immunohistochemical scores (IHCS), percentage of positive cells (PP), atypical ductal hyperplasia (ADH).

\section{Introduction:}

The risk of breast cancer and death due to breast cancer are clearly increasing worldwide. ${ }^{1}$ Carcinoma in situ of the breast (CIS) comprises a heterogeneous group of lesions, covering a wide spectrum of clinical conditions and histopathological changes. With respect to biological behavior, CIS range from biologically aggressive lesions with a substantial risk of progression into invasive carcinoma (IC), to lesions with a very low malignant potential. Previous studies of CIS indicate that approximately a third will subsequently develop IC. Autopsy studies indicate that CIS is frequently occurring and it was estimated that about $20 \%$ of all women will develop CIS during lifetime. ${ }^{2}$

Programmed cell death (apoptosis) may play a role in tumor development and progression. Dys-regulation of genes 
controlling apoptosis may cause mammary cells to become immortal and constitute a cancer. ${ }^{3}$ Programmed cell death is controlled by inhibitor of apoptosis proteins (IAP), which include bcl-2 family members that either promote (ie., Bax, Bcl-xS, Bad and Bid) or counteract (ie.,Bcl-2, Bcl-xL and Mcl-1) the signals that initiate apoptotic cell death. ${ }^{4}$

In this study, we aimed to evaluate the expression of apoptosis related proteins, bcl2, bax, bcl-xl and p53 protein in DCIS in relation to its grade. Furthermore, we tried to evaluate the possible correlations between these proteins which may have an impact on prognosis of DCIS and its progression to IC.

\section{Patients and methods:}

This study was done on 13 retrograde formalin-fixed paraffin-embedded specimens of DCIS of the breast. These specimens were obtained by lumpectomy, incisional or Trucut biopsies of breast masses which were sent to Histopathology Laboratory of Sohag University Hospital in the period between 2001- 2005. The diagnosis of DCIS was established by examination of Hematoxylin and Eosin (H\&E) stained sections.

DCIS was classified into three grades according to the criteria of Holland et al (1994), 5 into well-differentiated (grade I), moderately differentiated (grade II), and poorly differentiated DCIS (grade III). In specimens showing more than one histological grade, DCIS was graded according to the highest grade.

Immunohistochemical staining for all cases with antibodies for bcl-2, bax, bcl$\mathrm{xl}$ and p53 was performed using immunoperoxidase technique. Sections were pretreated by boiling for 9-15 $\mathrm{min}$ in citrate buffer ( $\mathrm{pH}$ 6.0). Incubation with the diluted primary antibody with $1 \%$ blocking anti-goat serum was applied for 1-2 hours. Antibodies used were mouse monoclonal antibodies for bcl-2 (Bcl-2 Ab 1, clone 100/D5, Catalogue number; Cat \# MS123-P0, LabVision), bax (Bax Ab1, clone 2D2, Cat \# MS -771-P0,
LabVision), bcl-xl (Bcl-xl Ab2, clone 7D9, Cat \# MS -1334-P1, LabVision ) and rabbit monoclonal antibody for p53 (clone Y5, Cat \# RM- 2103-R7, LabVision) at dilutions of 1/100 for bcl-2, bax and bcl-xl and 1/25 for $\mathrm{p} 53$. The sections were then incubated with the biotinylated secondary antibody (Ultravision plus large volume detection system, anti-polyvalent, HRP, Cat \# TP-060HLX, LabVision) for 15 min. All dilutions were made in phosphate buffered solution (PBS), at $\mathrm{pH} \mathrm{7.2,} \mathrm{and} \mathrm{all} \mathrm{of} \mathrm{the} \mathrm{incubations}$ were performed in humid chambers at room temperature. Between each two steps in the staining procedures (except before incubation with the primary antibody), the slides were rinsed three times in PBS. Finally, the sections were lightly counterstained in Mayer's Hematoxylin and mounted on glass slides using DPX (BDH Ltd, Poole, United Kingdom).

The immunostaining of bcl-2, bcl-xL, bax, and p53 was analyzed and evaluated in 10 different tumor fields. For p53, nuclear staining only was considered. ${ }^{6}$ Expression of $5 \%$ of tumor cells for the stain was considered as the threshold of positive staining, as the presence of more than $5 \%$ immunoreactivity may be associated with p53 mutations. ${ }^{7}$ For bcl-2, bax, and bcl-xl tumor cells were considered positive when they displayed a distinct micropunctate golden yellow cytoplasmic staining.

The mean percentage of tumor cells with positive staining was evaluated and scored as: 0 for $<5 \%, 1$ for 5-25\%, 2 for 25-50, 3 for 50-75, and 4 for $>75$ following Hussein et al (2004) ${ }^{8}$ and Baltaziak et al (2006). ${ }^{9}$

Staining intensity (SI) was also considered in the evaluation of the immunohistochemical expression of p53, bcl-2, bax, and bcl-xl. It is scored as; 1 for weak, 2 for medium, 3 for intense staining following Hussein et al (2004). ${ }^{8}$ Immunohistochemical scores (IHCS) were calculated by multiplying the percentage of positive cells (PP) with the staining intensity (SI). Validation of this method has been described elsewhere. 10 


\section{Statistical analysis:}

Chi-Square and Pearson's Correlation Coefficient tests were used to evaluate statistical significance of various markers in relation to the grade of DCIS, and in relation to each other, with a statistical significance of $\mathrm{p}<0.05$ for Chi-square test and $\mathrm{p}<0.02$ for Pearson's Correlation Coefficient test.

\section{Results:}

Relations between the estimated biological markers in DCIS and tumor grade: Tables (1-5) and Figures (1-2) illustrate the results of immunohistochemical expression of p53, bcl-2, bax and bcl-xl in DCIS of the breast. DCIS was graded into; 5/13 (42\%) low, 3/13 (16\%) intermediate, and 5/13 (42\%) high grade cases. Expression of p53 was negative in all low grades, positive in $2 / 3$ (66.7\%) intermediate grade, and in all high grade 5/5 (100\%) DCIS. Bcl-2 was positive in all cases of DCIS with variable intensities. Bax and Bcl-xl were positive in 4/5 (80\%) of low grade, and all (100\%) intermediate and high grade DCIS.

Relations between the estimated biological markers in DCIS of the breast: Figure (3) illustrates the correlations between the studied markers in DCIS of the breast. Statistically inverse relationship was present between p53 and bcl-2 expression in DCIS $(r=-0.636$, $\mathrm{p}<0.02$ ). Statistically insignificant positive relationship was present between p53 and bax expression and between p53 and bcl-xl expression in DCIS $(r=0.524, p<0.07$ for each). Significant inverse correlation was present between bcl-2 and bcl-xl expression and between bcl-2 and bax expression in DCIS $(r=-0.659, p<0.01$ for each). Significant positive correlation was present between bax and bcl-xl expression $(r=1.0$, $\mathrm{p}<0.000)$ in DCIS.

\section{Discussion:}

It is widely held that breast cancer initiates as the pre-malignant stage of atypical ductal hyperplasia $(\mathrm{ADH})$, progresses into the preinvasive stage of DCIS, and culminates in IC. ${ }^{11}$ In the current study we tried to investigate the immunohistochemical expression of some important apoptosis related gene products namely; bcl-2, bax, and bcl-xl proteins and tumor suppressor gene p53; in 15 cases of breast in situ carcinoma in relation to tumor grade. We also tried to find possible relationships between expressions of these proteins in DCIS.

Our study showed that, p53 is expressed in areas of in situ carcinoma in 7/13 (48\%), and it's expression correlated positively with higher tumor grade $(p<0.004)$ in agreement with Mao et al, (2010), ${ }^{12}$ who found that the frequency of p53 missense mutations was significantly different among the three overall histological grade categories of DCIS; in $0 / 49$ (0\%) of low, $1 / 23$ (4.35\%) of intermediate, and 9/22 (40.9\%) of high-grade DCIS $(\mathrm{P}<.0001)$. This finding indicated that p53 mutations usually occur before invasion during breast cancer progression, and that p53 protein expression in DCIS is an important indicator of cancer invasiveness and prognosis of DCIS. ${ }^{13}$

In agreement with Kayaselcuk et al, (2004), ${ }^{14}$ bcl-2 expression was not correlated with the grade of DCIS, which suggests that alterations in bcl-2 expression in breast carcinoma are more prominent in invasive rather than in in situ lesions.

In agreement with Rehman et al, (2000), ${ }^{15}$ and Kayaselcuk et al, (2004), ${ }^{14}$ who found that bax expression did not correlate with increasing histological grades of DCIS, we found insignificant correlation between bax expression and tumor grade of DCIS. Contradictory findings were obtained by Kapucuoglu et al, (1997) ${ }^{16}$ and Anagnostopoulos et al, (2007), ${ }^{17}$ who found that bax protein expression in DCIS was related to more aggressive neoplasms. Bcl$\mathrm{xl}$ expression did not correlated to tumor grade of DCIS $(\mathrm{p}<0.3)$, in concordance with Kayaselcuk et al, (2004). ${ }^{14}$ This finding is contradictory to the findings of Fernandez et al, (2000), ${ }^{18}$ and Espanña, et al, (2005) ${ }^{15}$ who found positive correlation between bcl-xl expression and grade of DCIS. This controversy reflects the complexity of bax and bcl-xl regulation and the need for more studies for these genes on both immunohistochemical 
and molecular levels.

Bcl-2 is one member of a gene family, products of which are involved in either inhibition or promotion of cell death. ${ }^{20} \mathrm{~A}$ large number of bcl-2 related proteins have been isolated. Protein products of this gene family share two highly conserved domains BH 1 \& BH 2. ${ }^{21}$ It is divided into 3 categories (Tsujimoto and Shimizu, 2000): 1. Antiapoptotic members such as bcl-2, bcl-xl, bcl-w \& Mcl-1 and all of which exerts an anti-cell death activity and share sequence homology, particularly within the four regions $\mathrm{BH} 1$ through $\mathrm{BH}$ 4. 2. Pro-apoptotic members such as bax, bak and bad, which share sequence homology in $\mathrm{BH} 1, \mathrm{BH} 2$ and $\mathrm{BH} 3$ but not $\mathrm{BH}$ 4. 3. BH3 only proteins, which include bik, bid and bim and share sequence homology only in BH3. They interact with bcl-2 and antagonize its survival function.

One of the unique features of bcl-2 family is their ability to physiologically bind each other forming a complex network of homoand/or heterodimers. ${ }^{22}$ The above domains $\mathrm{BH} 1$ and $\mathrm{BH} 2$ regulate heterodimerization, and regulation of cell death by members of this gene family may be achieved through competing dimerization. ${ }^{23}$ They regulate apoptosis in a rheostatic manner: in an excess of bax, for instance, bax homodimers predominate which favors apoptosis. ${ }^{24}$ Conversely, in an excess of bcl-2, bcl-2/ bax heterodimers are formed, which lead to inhibition of apoptosis. Competition between family members also has an effect. Bcl-xL for example, inhibits and sequestering bax. By binding bcl-2 and bcl-xL, bad on the other hand, releases bax, which leads to bax homodimerization and promotion of apoptosis. ${ }^{25}$

Many members of the bcl-2 family such as bcl-2, bcl-xL and bax, are resident proteins of the mitochondrial membranes, endoplasmic reticulum and nuclear envelope in which they are inserted via their carboxyl terminal ends. In the mitochondria, they form pores and act as ion channels. This is probably the key to their function in apoptosis. Namely induction of apoptosis is almost invariably accompanied by disruption of the mitochondrial transmembrane potential and release of caspase- activating substances, such as cytochrome $\mathrm{C}$ and AIF, from the mitochondria. 25

As the expression of this gene family seems to be differentially regulated among cell types and their stage of differentiation, so biological impact of any bcl-2 family member on a cell is dependent on the level, selective expression, and dimerization status of the gene family. ${ }^{26,27}$

The death antagonistic and death promoting members of the bcl-2 family function as potential oncogenes and tumor suppressor genes respectively. The Darwinian selection of cancer cells by adverse intrinsic conditions (limited trophic supply, oxygen shortage), and/or therapeutic agents (chemotherapy, radiotherapy) may favor survival of the proliferating cells, which overexpress antiapoptotic gene products. ${ }^{28}$

We found an inverse relationship between p53 and bcl-2 which is statistically significant $(\mathrm{p}<0.02)$ in agreement with several authors. ${ }^{29-31}$ Interestingly, it has been demonstrated that in human breast carcinoma cell lines, a mutated and/or wild-type p53 down-regulates bcl-2 expression. ${ }^{32}$

Although p53 is a direct transcriptional activator of bax, ${ }^{33,34}$ statistically insignificant relationship was present between p53 and bax expression in DCIS of the breast in agreement with Veronese et al, (1997), ${ }^{35}$ Rehman et al, (2000), ${ }^{36}$ and Baccouche et al, (2003). ${ }^{37}$ This indicates that regulation of bax is complex, and may be explained by the presence of p53 mutations which affect its interaction with bax protein, or by intervention of other molecules which may modulate the function of either or both proteins. ${ }^{36}$

In the current study, negative correlation between bax and bcl-2 expression was detected in DCIS $(\mathrm{p}<0.01)$, which concurs with Kapucuoglu et al, (1997), ${ }^{38}$ who found that while both proteins were expressed at the same time in normal and benign epithelium, different staining patterns were observed according to the degree of differentiation of the neoplastic epithelium.

In this study inverse correlation was present between bcl-2 and bcl-xl expression 

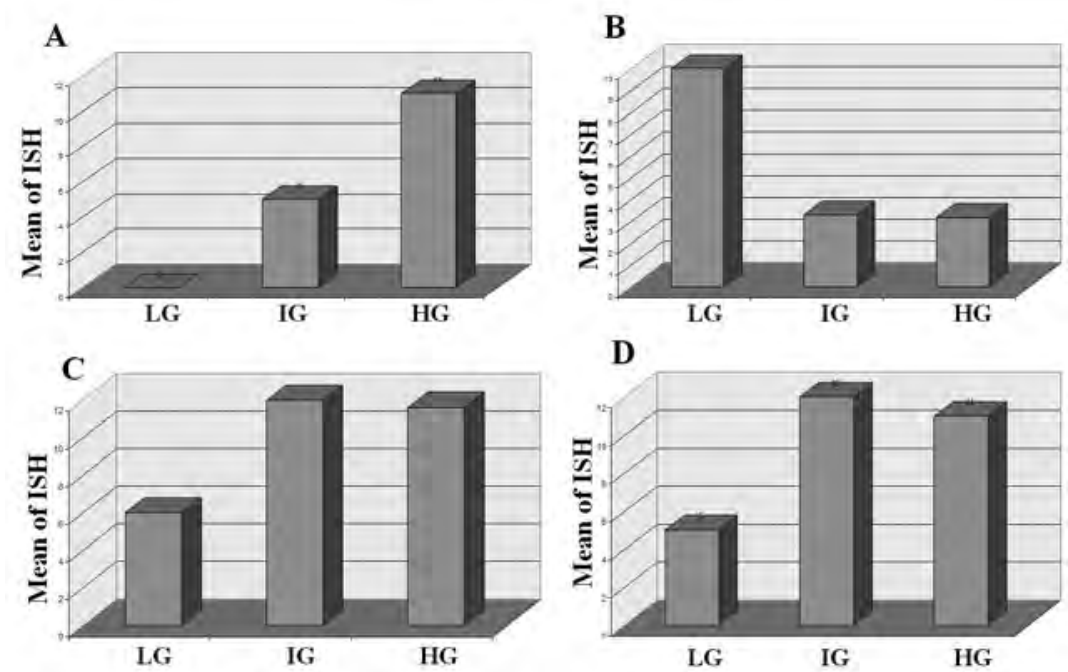

Figure (1): A. P53, B. Bcl-2, C. Bax and D. Bcl-xl expression in DCIS according to tumor grade.
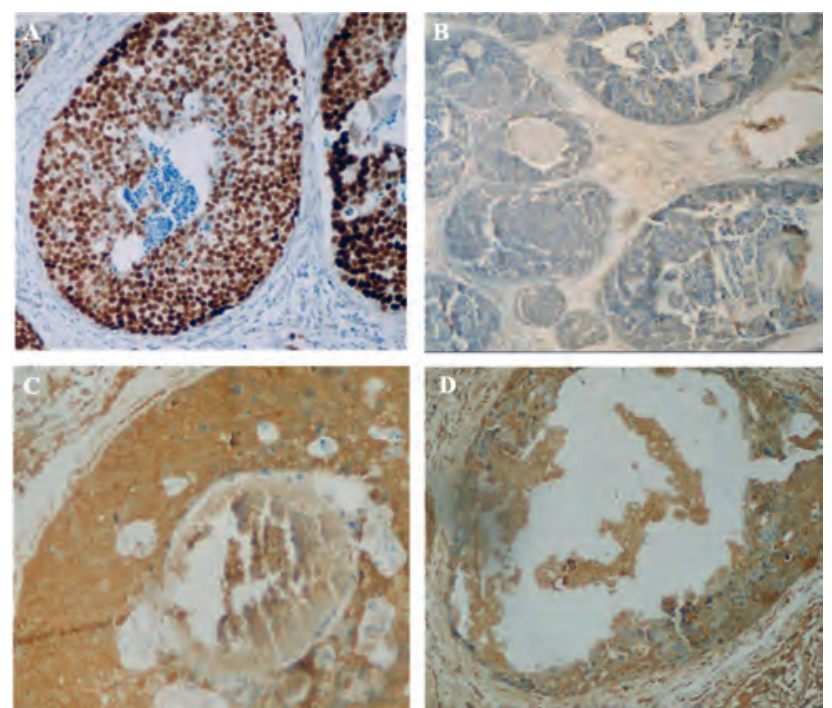

Figure (2): A. Strong p53, B. weak bcl-2, C. Strong bax and D. Strong bcl-xl expression in comedo $(A \& B)$ and cribriform $(C \& D)$ DCIS of the breast. Magnifications: $X 200(A \& B)$ and $X 400(C \& D)$.

in DCIS of the breast $(\mathrm{p}<0.01)$. This finding can be explained by that although bcl-2 and bcl-xl are homologues and both of them encode membrane-associated proteins that protect neoplastic cells from DNA damageinduced apoptosis, differential expression and regulation of bcl-2 and bcl-xl in different tumors is present. 39

Although bax gene is proapoptotic and bcl-xl is antiapoptotic, highly significant positive correlation was present between bax expression and bcl-xl expression $(\mathrm{p}<0.000)$ in DCIS. This is in agreement with Guo et al, (2002), ${ }^{40}$ Baltaziak et al, (2006), ${ }^{44}$ and
Wincewicz et al, (2007), ${ }^{42}$ who found a positive correlation between bcl-xl and bax in several types of malignant tumors. This result could be due to possible heterodimerization of bax and bcl-xl, ${ }^{43,44}$ which may affect the expression of both or either proteins.

We conclude that p53 mutation is an early event in evolution of breast cancer and its expression correlates with high grade lesions. In addition, it appears that the relation between bcl-2 family members is too complex, with strong positive correlation between bax and bcl-xl, and that their prognostic value is less important in DCIC of the breast than in IC. 
A
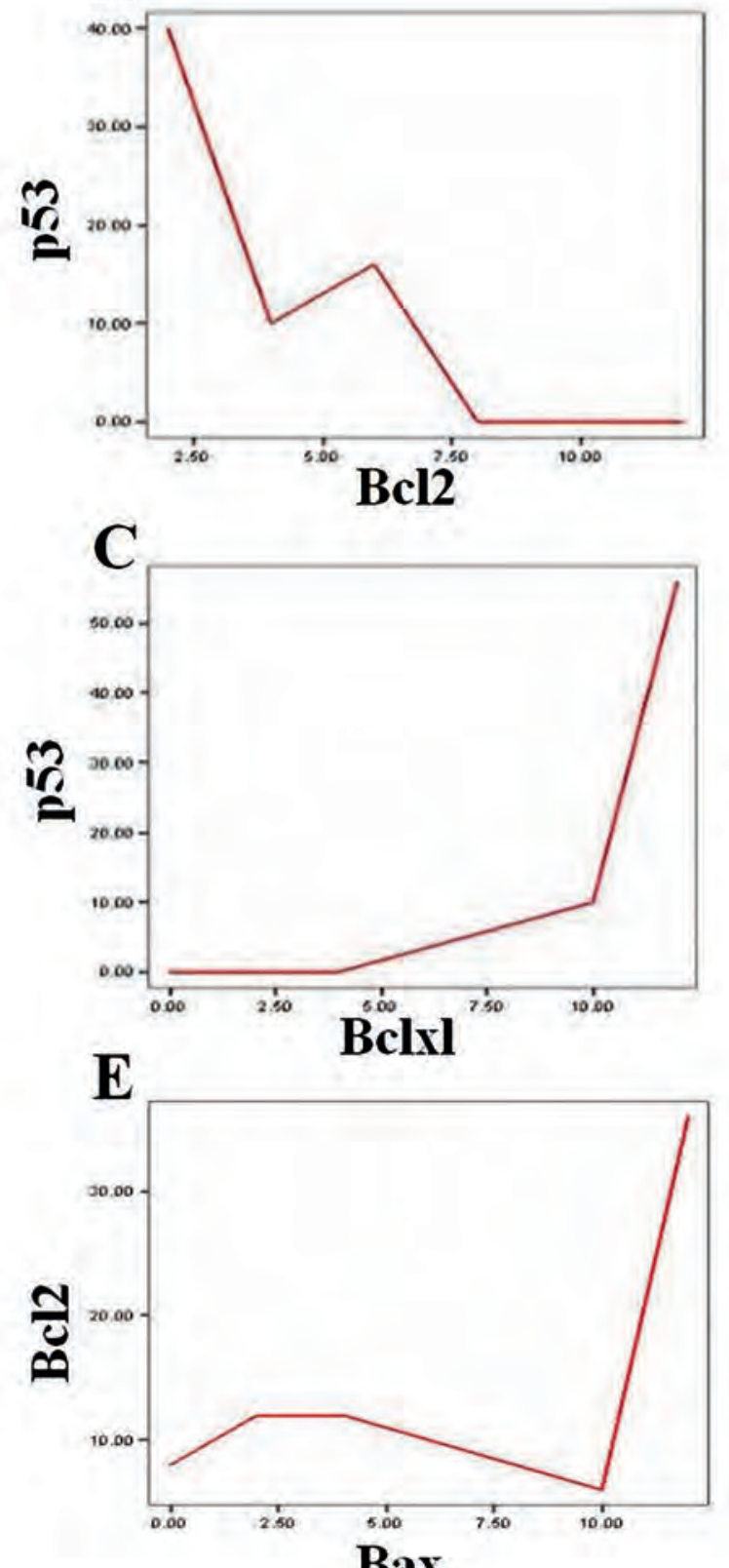

B

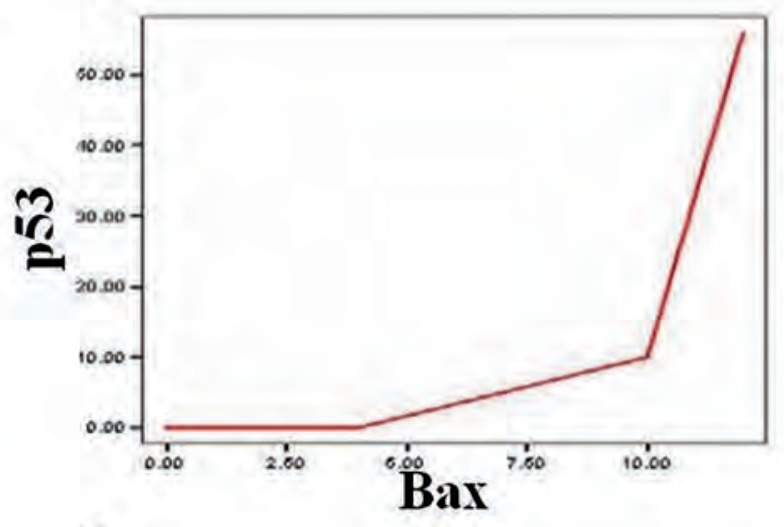

D
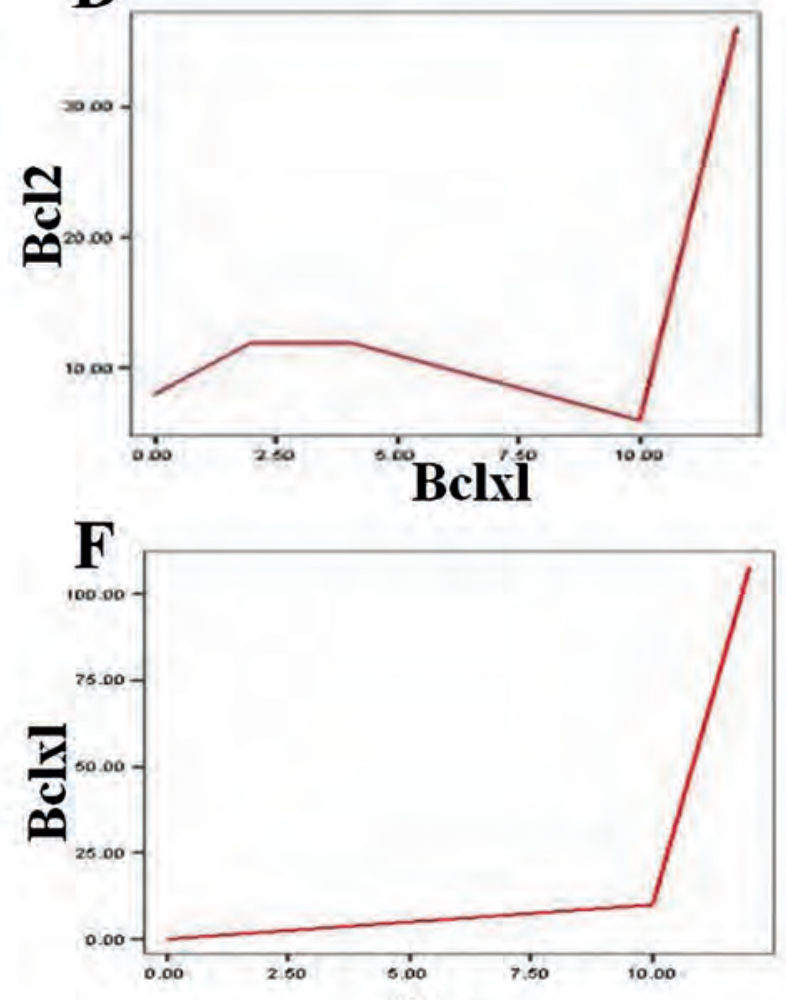

Bax

Figure (3): Relation between A. P53 and bcl-2, B. P53 and bax, C. P53 and bcl-xl, D. bcl-2 and bcl-xl, E. bcl-2 and bax, and bax and bcl-xl in DCIS of the breast.

\section{Reference:}

1- Porter PN: Westernizing” women's risks? Breast cancer in lower-income countries. Engl J Med 2008; 358: 213-216.

2- Ottesen G: Carcinoma in situ of the female breast. A clinico-pathological, immunohistological, and DNA ploidy study. APMIS Suppl 2003; 23: 1-67.

3- Moreno A, Figueras A, Lloveras B, Escobedo A, Griera E, Sierra A, Fabra A: Apoptosis in ductal carcinoma of the breast. Breast $J$ 2001; 7: 245-248
4- Kayaselcuk F, Nursal T, Polat A, Noyan T, Yildirim S, Tarim A, Seydioglu G: Expression of Survivin, bcl-2, p53 and bax in breast carcinoma and ductal intraepithelial neoplasia (DIN 1a). J Exp Clin Cancer Res., 2004; 23: 105-112

5- Holland R, Peterse JL, Millis RR: Ductal carcinoma in situ: A proposal for a new classification. Semin Diagn Pathol 1994; 11: 167-180.

6- Oldenburg RA, Kroeze-Jansema K, MeijersHeijboer H, van Asperen CJ, Hoogerbrugge 
Table (1): P53 expression in DCIS according to tumor grade.

\begin{tabular}{|l|l|l|l|l|l|l|}
\hline \multicolumn{1}{|c|}{ Tumor grade } & No & Negative & Mild & Moderate & Strong & IHS (X \pm SD) \\
\hline Low grade & 5 & $5(100 \%)$ & - & - & - & $0 \pm 0$ \\
\hline Intermediate grade & 3 & $1(33.3 \%)$ & - & $2(66.7 \%)$ & - & $4.7 \pm 4.2$ \\
\hline High grade & 5 & - & - & $1(20 \%)$ & $4(80 \%)$ & $10.5 \pm 1.7$ \\
\hline P value & \multicolumn{5}{|c|}{0.004} \\
\hline
\end{tabular}

Table (2): Bcl-2 expression in DCIS according to tumor grade.

\begin{tabular}{|l|l|l|c|l|l|l|}
\hline \multicolumn{1}{|c|}{ Tumor grade } & No & Negative & Mild & Moderate & Strong & IHS (X \pm SD) \\
\hline Low grade & 5 & - & $1(20 \%)$ & $1(20 \%)$ & $3(60 \%)$ & $9.6 \pm 3.6$ \\
\hline Intermediate grade & 3 & - & $2(66.7)$ & $1(33.3)$ & - & $3.3 \pm 2.3$ \\
\hline High grade & 5 & - & $4(80 \%)$ & $1(20 \%)$ & - & $3.2 \pm 1.8$ \\
\hline P value & \multicolumn{7}{|c|}{0.1} \\
\hline
\end{tabular}

Table (3): Bax expression in DCIS according to tumor grade.

\begin{tabular}{|l|l|l|l|l|c|l|}
\hline \multicolumn{1}{|c|}{ Tumor grade } & No & Negative & \multicolumn{1}{c|}{ Mild } & Moderate & Strong & IHS (X \pm SD) \\
\hline Low grade & 5 & $1(20 \%)$ & $2(40 \%)$ & - & $2(40 \%)$ & $6 \pm 5.7$ \\
\hline Intermediate grade & 3 & - & - & - & $3(100 \%)$ & $12 \pm 0.0$ \\
\hline High grade & 5 & - & - & - & $5(100 \%)$ & $11.6 \pm 0.9$ \\
\hline P value & \multicolumn{6}{|c|}{0.2} \\
\hline
\end{tabular}

Table (4): Bcl-xl expression in DCIS according to tumor grade.

\begin{tabular}{|l|l|l|l|l|c|l|}
\hline \multicolumn{1}{|c|}{ Tumor grade } & No & Negative & \multicolumn{1}{c|}{ Mild } & Moderate & Strong & IHS $(\mathrm{X} \pm \mathrm{SD})$ \\
\hline Low grade & 5 & $1(20 \%)$ & $2(40 \%)$ & - & $2(40 \%)$ & $5 \pm 5.7$ \\
\hline Intermediate grade & 3 & - & - & - & $3(100 \%)$ & $12 \pm 0.0$ \\
\hline High grade & 5 & - & - & $1(20 \%)$ & $4(80 \%)$ & $10.8 \pm 1.8$ \\
\hline P value & \multicolumn{6}{|c|}{0.3} \\
\hline
\end{tabular}

Table (5): Relations between the investigated apoptosis markers in DCIS (Pearson's correlation coefficient; $r$ value).

\begin{tabular}{|l|l|l|l|l|}
\hline Factor & p53 & Bcl-2 & Bax & Bcl-xl \\
\hline p53 & ------ & -0.636 & 0.524 & 0.524 \\
\hline Bcl-2 & ------ & ------ & -0.659 & -0.659 \\
\hline Bax & ------ & ------ & ----- & 1.0 \\
\hline
\end{tabular}

$\mathrm{N}$, van Leeuwen I, Vasen HFA, CletonJansen AM, Kraan J, Houwing-Duistermaat JJ, Morreau H, Cornelisse CJ, Devilee P: Characterization of familial non-BRCA1/2 breast tumors by loss of heterozygosity and immunophenotyping. Clin Cancer Res 2006; 12: $1693-1700$.
7- Wikonkal NM, Berg RG, van Haselen CW, Horkay I, Remenyik E, Begany A, Hunyadi J, van Vloten WA, de Gruijl FR: Bcl-2 vs p53 protein expression and apoptotic rate in human nonmelanoma skin cancers. Arch Dermatol 1997; 133: 599-602.

Hussein MR, Al-Badaiwy ZH, Georgis MN: 
Analysis of p53 and bcl-2 protein expression in the non-tumourigenic, pretumourigenic and tumourigenic keratinocytic hyperproliferative lesions. $J$ Cut Pathol 2004; 244: 1-9.

8- Baltaziak M , Duraj E, Koda M, Wincewicz A, Musiatowicz M, Koda LK, Szymanska M, Lesniewicz T, Muslatowwic B: Expression of bcl-xl, bax, and p53 in primary tumours and lymph node metastases in oral squamous cell carcinoman. Ann NY Acad Sci 2006; 1090: 18-25.

9- Damron TA, Mathur S, Horton JA, Strauss J, Margulies B, Grant W, Farnum CE, Spadaro JA: Temporal changes in PTHrP, bcl-2, bax, caspase, TGF- $\beta$, and FGF-2 expression following growth plate irradiation with or without radioprotectant. Histochem. \& Cytochem. 2004; 52: 157-167.

10- Ma ZJ , Salunga R, Tuggle JT: Gene expression profiles of human breast cancer progression. Gene expression profiles of human breast cancer progression. PNAS 2003; 100: 5974-5979.

11- Mao X, Fan C, Wei J, Yao F, Jin F: Genetic mutations expression of p53 in non-invasive breast lesions. Mol Med Report 2010; 3(6): 929-934.

12- Rajan PB, Scott DJ, Perry RH, Griffith CDM: P53 protein expression in ductal carcinoma in situ (DCIS) of the breast. Br Cancer Res Treat 1997; 24: 283-290.

13- Kayaselcuk F, Zorludemir S, Bal N, Erdogan B, Erdogan S, Erman T: The expression of survivin and Ki-67 in meningiomas: Correlation with grade and clinical outcome. J Neurooncol. 2004; 1\&2: 209-214.

14- Rehman S, Crow J, Revell PA: Bax protein expression in DCIS of the breast in relation to invasive ductal carcinoma and other molecular markers. Pathol Oncol Res 2000; 6: 256-263.

15- Kapucuoglu N, Losi L, Eusebi V: Immunohistochemical localization of bcl-2 and bax proteins in situ and invasive duct breast carcinomas. Virchows Archiv 1997; 430: 17-22.

16- Anagnostopoulos GK, Stefanou D, Arkoumani E, Chalkley L, Karagiannis J, Paraskeva K, Mathou N, Dellaporta E, Tsianos E, Agnantis NJ: Expression of bax protein in gastric carcinomas. A clinicopathological and immunohistochemical study. Acta Gastroenterol Belg 2007; 70: 285-289.

17- Fernández Y, España L, Mañas S, Fabra
A, Sierra D: Bcl-xl promotes metastasis of breast cancer cells by induction of cytokines resistance. Cell Death and Differ 2000; 4: 350-359.

18- España L, Martín B, Aragüés R, Chiva C, Oliva B, Andreu D, Sierra A: Bcl-xlmediated changes in cetabolic pathways of breast cancer cells from survival in the blood stream to organ-specific metastasis. Am J Pathol 2005; 167: 1125-1137.

19- Korsmeyer S: Bcl-2 gene family and the regulation of programmed cell death. Cancer Res 1999; 1: 1693-1700.

20- White E: Life, death and the pursuit of apoptosis. Gene Dev. 1996; 10: 1-15

21- Reed J: Expression and location of proapoptotic bcl-2 family protein bad in human tissues and tumor cell lines. Am $J$ Pathol 1998; 152: 51-61.

22- LU Q, Abel P, Foster C and LaLani E: Bcl-2: Role in epithelial differentiation and oncogenesis. Human Pathol 1996; 27: 102-110.

23- Yang E, Zha J, Jockel J, Boise L, Thompson C Korsmeyer S: Bad, a heterodimeric partner for bcl-XL and bcl-2, displaces bax and promotes cell death. Cell 1995; 80: 285-291.

24- Kroemer G: The proto-oncogene bcl-2 and its role in regulating apoptosis. Nat Med 1997; 3: 614-620.

25- Oltvai ZN, Milliman CL, Korsmeyer SJ: Bcl2 heterodimerizes in vivo with a conserved homolog, bax that accelerates programmed cell death. Cell 1993; 74: 609-619.

26- Yang E, Zha J, Jockel J, Boise L, Thompson C Korsmeyer S: Bad, a heterodimeric partner for bcl-XL and bcl-2, displaces bax and promotes cell death. Cell 1995; 80: 285-291.

27- Zamzami N, Brenner C, Marzo I, Susin I, Susin S Kroemer G: Subcellular and submitochondrial mode of action of bcl2 like oncoproteins. Oncogene 1998; 16: 2265-2282.

28- Ioachim EE, Malamou-Mitsi V, Kamina SA, Goussia AC, Agnantis NJ: Immunohistochemical expression of bcl2 protein in breast lesions: correlation with bax, p53, Rb, C-erbB-2, EGFR and proliferation indices. Anticancer Res 2000; 20: 4221-4225.

29- Skarlos D, Gogas H, Kiriakou V, Margariti A, Kirkou E, Pavlaki E, Asimaki A, Toliou T, Tziortziotis D, Vamvouka C, Fountzilas G: Evaluation of the prognostic value of p53 and Bcl-2 in breast cancer patients participating in a randomized study with dose-dense 
sequential adjuvant chemotherapy (DSAC). J Clin Oncol 2005; 23: 627-637.

30- Tsutsui S, Yasuda K, Suzuki K, Takeuchi H, Nishizaki T, HigashI H, Era S: Bcl-2 protein expression is associated with p27 and p53 protein expressions and MIB-1 counts in breast cancer. BMC Cancer 2006; 6:187: 1471-2407.

31- Haldar S, Negrini M, Monne M: Downregulation of bcl-2 by p53 in breast cancer cells. Cancer Res 1994; 54: 2095-2097.

32- Miyashita T, Reed J: Tumor suppressor p53 is a direct transcriptional activator of the human bax gene. Cell 1995; 80: 293-299.

33- De Feudis P, Vignati S, Rossi C, Mincioni T, Giavazzi R, D’Incalci M, Broggini M: Driving p53 response to bax activation greatly enhances sensitivity to taxol by inducing massive apoptosis. Neoplasia 2000; 2: 202-207.

34- Veronese S, Mauri FA, Caffo O, Scaioli M, Aldovini D, Perrone G, Galligioni E, Doglioni C, Palma PD, Barbareschi M: Bax immunohisto-chemical expression in breast carcinoma: A study with long term followup. Pred Oncol 1998; 79: 13-18.

35- Rehman S, Crow J, Revell PA: Bax protein expression in DCIS of the breast in relation to invasive ductal carcinoma and other molecular markers. Pathol Oncol Res 2000; 6: 256-263.

36- Baccouche S, Daoud J, Frikha M, Mokdad-Gargouri R, Gargouri A, Jlidi R: Immunohistochemical status of p53, MDM2, bcl-2, bax, and ER in invasive ductal breast carcinoma in Tunisian patients. Ann $N Y$ Acad Sci 2003; 1010: 752-763.
37- Kapucuoglu N, Losi L, Eusebi V: Immunohistochemical localization of bcl-2 and bax proteins in situ and invasive duct breast carcinomas. Virchows Archiv 1997; 430: $17-22$.

38- Findley HW, Lubing Gu, Yeager AM, Zhou M: Expression and regulation of bcl-2, bcl$\mathrm{xl}$, and bax correlate with p53 status and sensitivity to apoptosis in childhood acute lymphoblastic leukemia. Blood 1997; 89: 2986-2993.

39- Guo XZ, Shao XD, Liu MP, Xu JH, Ren LN, Zhao JJ, Li HY, Wang D: Effect of bax, bcl-2 and bcl-xl on regulating apoptosis in tissues of normal liver and hepatocellular carcinoma. World J Gastroenterol 2002; 8: 1059-1062.

40- Baltaziak M, Duraj E, Koda M, Wincewicz A, Musiatowicz M, Koda LK, Szymanska M, Lesniewicz T, Muslatowwic B: Expression of bcl-xl, bax, and p53 in primary tumours and lymph node metastases in oral squamous cell carcinoman. Ann NY Acad Sci 2006; 1090: 18-25.

41- Wincewicz A, Sulkowska M, Koda M, Kanczuga-Koda L, Witkowska E, Sulkowski S: Significant coexpression of GLUT-1, bclxl, and bax in colorectal cancer. Ann NY Acad Sci 2007; 1095: 53-61.

42- Chao DT, Linette GP, Boise LH, White LS, Thompson CB, Korsmeyer SJ: Bcl-xl and bcl-2 repress a common pathway of cell death. $J$ Exp Med 1995; 1:182: 821-828.

43- Hattori T, Ookawa N, Fujita R, Fukuchi K: Heterodimerization of bcl-2 and bcl-xl with bax and Bad in Colorectal Cancer. Acta Oncologica 2000; 39: 495-500. 